\title{
Reflection of equatorial Kelvin waves at eastern ocean boundaries Part II: Pacific and Atlantic Oceans
}

\author{
J. Soares ${ }^{1}$, I. Wainer ${ }^{2}$, N. C. Wells ${ }^{3}$ \\ ${ }^{1}$ Dept. de Ciências Atmosféricas, Rua do Matão 1226, Universidade de São Paulo, SP, Brazil, 05508-900 \\ ${ }^{2}$ Dept. de Oceanografia Física, Praça do Oceanográfico 191, Universidade de São Paulo, SP, Brazil, 05508-900 \\ ${ }^{3}$ Southampton Oceanography Centre, European Way, Southampton, SO14 3ZH, UK
}

Received: 19 September 1997 / Revised: 26 August 1998 / Accepted: 19 October 1998

\begin{abstract}
The effect of viscosity, non linearities, incident wave period and realistic eastern coastline geometry on energy fluxes are investigated using a shallow water model with a spatial resolution of $1 / 4$ degree in both meridional and zonal directions. Equatorial and mid-latitude responses are considered. It is found that (1) the influence of the coastline geometry and the incident wave period is more important for the westward energy flux than for the poleward flux, and (2) the effect of the inclination of the eastern ocean boundary on the poleward energy flux, for the Pacific and Atlantic Oceans, decline as the period of the incident wave increases. Furthermore, the model simulations suggest that the poleward energy fluxes from meridional boundaries give plausible results for motions of seasonal and annual periods. For comparatively shorter periods, a realistic coastline geometry has to be included for more accurate results. It is recommended that any numerical model involving the reflection of baroclinic Rossby waves (of intraseasonal, seasonal or annual periods) on the eastern Pacific or Atlantic Oceans, should consider the effect of the coastline geometry in order to improve the accuracy of the results.
\end{abstract}

Key words. Oceanography: general (climate and interannual variability; equatorial oceanography). Oceanography: physical (eastern boundary currents).

\section{Introduction}

Equatorial Kelvin waves are thought to occur over a wide range of frequencies. Sea level records from El Niño years reveal that sustained periods of high sea level

Correspondence to: $\mathbf{J}$. Soares were composed of several wave periods, which were interannually modulated (Madden and Julian, 1971, 1972; Ripa and Haynes, 1981; Enfield, 1989; McPhaden and Taft, 1988; Miller et al., 1988; Glantz et al., 1990; Weickman, 1991; Delcroix et al., 1991; among others). Upon impingement with the eastern boundary, the incoming baroclinic equatorial Kelvin wave excites westward-propagating Rossby waves and polewardpropagating coastal Kelvin waves (Moore, 1968; Moore and Philander, 1977; McCreary, 1976).

The low-frequency response of sea level on the eastern ocean boundaries can be subdivided for linear purposes into two independent constituents (1) the remotely forced part, i.e., that which is the result of an equatorial Kelvin wave incident on the boundary, and (2) the locally forced part. The latter is due to the longshore component of the wind (Bigg and Gill, 1986).

Observational and theoretical studies, however, have indicated that the remotely forced part dominates the sea level variability along the eastern coasts of North and South America, related to the interannual frequency, as in the ENSO phenomenon (Enfield and Allen, 1980; Chelton and Davis, 1982; Pares-Sierra and O'Brien, 1989; Johnson and O'Brien, 1990; Spillane et al., 1986).

In the Atlantic ocean, observations suggest that the upwelling event in the Gulf of Guinea is not associated with either the local winds or the local ocean circulation (Houghton, 1976). A possible explanation is that a strong upwelling signal, generated by increased westward wind stress in the western Atlantic, can travel as an equatorial Kelvin wave (Moore et al., 1978; Adamec and O'Brien, 1978; Servain et al., 1982; Busalacchi and Picaut, 1983; Picaut, 1983; McCreary et al., 1984; Katz, 1987; Verstraete, 1992). This interpretation is analogous to the theories of El Niño in the Pacific ocean.

The nature of the response at an eastern boundary to an incident baroclinic Kelvin wave depends on the latitude, $\theta$, and on the wave period. For low frequencies a critical latitude, $\theta_{c}$ exists such that for $|\theta|<\theta_{c}$ the response consists of offshore-propagating Rossby 
waves, whereas for $|\theta|>\theta_{c}$ the waves are trapped by the coastal. The magnitude of the critical latitude decreases as the wave period decreases and as the coastline inclination $(\gamma)$, from meridional orientation, increases. (Grimshaw and Allen, 1988; Clarke and Shi, 1991).

Soares et al. (1998) using a viscous baroclinic shallow water model, have investigated the effects of viscosity, non-linearity, angle of coastline inclination and incident wave period on the baroclinic equatorial Kelvin waves at eastern ocean boundaries. They have found, by energy flux considerations, that the impact of viscosity is greater than the effect of non-linearities. A systematic decrease of coastal Kelvin wave energy as the wave period increases (and $\theta_{c}$ increases), predicted by inviscid theories (as in Clarke and Shi, 1991) was not verified in their work, because of the role of energy dissipation in their model. The dissipation was found to be dependent not only on the presence of the coastal Kelvin waves in the domain, but also on the period of these coastal waves. The influence of the angle of coastline inclination and of the incident wave period was found to be more important for the westward energy flux than for the poleward flux.

The main aim of this study is to investigate the behavior of the low-frequency baroclinic equatorial Kelvin waves when they reach the Pacific and Atlantic Ocean eastern coasts. Three different Kelvin wave periods are considered: intraseasonal, seasonal and annual. Some of the questions we address are: how far from the equator can the baroclinic disturbances propagate? How important is the coastline geometry on the propagation of the coastally trapped Kelvin waves and on the generation of the reflected Rossby waves? How important is the viscous effects on the studied waves? Are there differences between propagation in the Northern and Southern Hemispheres of the Pacific and Atlantic Oceans?

\section{Numerical model}

Non linear, 1/2 layer, shallow-water equations are used as the basis of the numerical model. The model is described in detail in Soares (1994) and Soares et al. (1998). Spherical coordinates with $\lambda$ (longitude) increasing eastward and $\theta$ (latitude) increasing northward are used in the model because of its large latitudinal extent. A regular 1/4 degree resolution is used in both zonal and meridional directions $\left(\Delta \lambda=\Delta \theta=1 / 4^{\circ}\right)$. Linear and nonlinear experiments are performed using a time step $(\Delta t)$ of 4 and $2 \mathrm{~h}$, respectively. A Laplacian coefficient of $10^{3} \mathrm{~m}^{2} \mathrm{~s}^{-1}$ is employed in the numerical experiments described in this work. The coefficient value, $10^{3} \mathrm{~m}^{2} \mathrm{~s}^{-1}$, has been commonly used in baroclinic shallow-water numerical models. Numerically, this coefficient helps to smooth the very high wave number numerical noise. Physically, $A_{H}$ helps to form a viscous boundary layer required to fit the observations with the theory. The effects of viscosity on linear free baroclinic Kelvin waves in shallow-water models have been discussed by Davey et al. (1983) and Hsieh et al. (1983).
A modification of Orlanski's (1976) radiative boundary condition (Miller and Thorpe, 1981) was used in all open boundaries: north, south and west. With the present scheme perturbations generated inside the domain are able to cross the artificial boundaries without distortion and without affecting the interior solution. On the solid boundaries the free-slip condition is used.

\section{Experiments}

The free wave solutions generated by the reflection of a baroclinic Kelvin wave at the eastern Pacific and Atlantic Ocean boundaries is investigated using the numerical model, outlined already with one layer of initial thickness, $H_{0}=200 \mathrm{~m}$. A pulse of finite width is used as surrogate to the baroclinic equatorial Kelvin wave. The maximum amplitude of the initial disturbance is taken as $30 \mathrm{~m}$. From the hydrostatic balance, a $30 \mathrm{~m}$ depression of the interface, implies a $10 \mathrm{~cm}$ surface elevation (considering $\rho_{2}=1060$ and $\rho_{1}=1025 \mathrm{Kg} \mathrm{m}^{-3}$ ). The wave meridional structure is assumed to be a Gaussian function of latitude centered on the equator. The linear phase speed is assumed to be $2.45 \mathrm{~ms}^{-1}$. Only half a wavelength of the initial disturbance is used in the experiments.

The eastern Pacific and Atlantic coastlines (Fig. 1) use the contour of $200 \mathrm{~m}$ depth line in the boundary calculations instead of the actual coastline, because it is a better approximation of the vertical coast assumed in theory. The initial layer thickness is considered to be $200 \mathrm{~m}$.

To estimate reflection properties it is convenient to consider the energy flux. Outwards along the boundary the energy flux is due to poleward coastal Kelvin waves. Depending on the hemisphere in consideration the poleward energy flux $\left(t_{P}\right)$ can be northward $\left(t_{N}\right)$ or southward $\left(t_{S}\right)$. The net energy flux toward the boundary $(t)$ is given by the difference between the energy fluxes due to the incoming equatorial Kelvin wave $\left(t_{E}\right)$ and due to the reflected Rossby waves $\left(t_{W}\right)$. Therefore, $t_{E}-t_{W}=t_{N}-t_{S}-t_{D}$; where $t_{D}$ is the energy dissipation. It was assumed that the energy flux is positive to the north and east directions.

Three different wave period (as in Soares et al., 1998) are considered: intraseasonal ( $T=60$ days), seasonal ( $T=180$ days $)$ and annual $(T=360$ days $)$.

In all the experiments, the numerical model is integrated for a time long enough to allow for the coastal Kelvin wave, generated by the equatorial wave to leave the domain.

\subsection{Energy flux considerations}

The fluxes are numerically calculated considering a region longitudinally bounded by an eastern ocean boundary $\left(\lambda=\lambda_{\text {coast }}\right)$ and a longitude away from the coast $\left(\lambda=-\lambda_{0}\right)$ and latitudinally bounded by $\theta= \pm \theta_{0}$ (where $\theta_{0}$ is the latitude in consideration, positive 

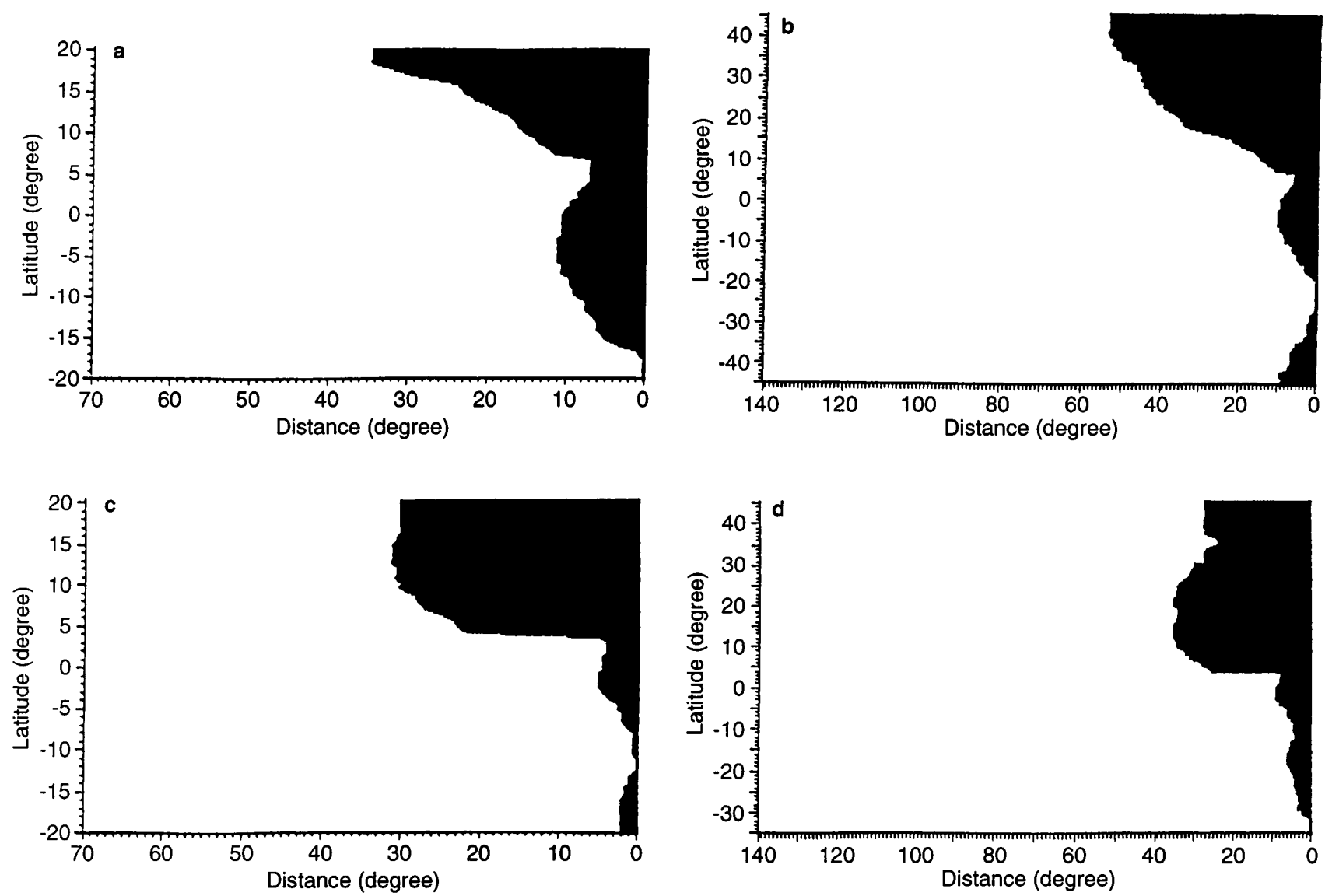

Fig. 1a-d. Model geometry. Pacific Ocean eastern coastline used for the a intraseasonal experiment and b for the seasonal and annual experiments; Atlantic Ocean eastern coastline used for the $\mathbf{c}$ intraseasonal experiment and $\mathbf{d}$ seasonal and annual experiments

northwards). This work assumes that the energy flux due to Kelvin wave can be separated from the one due to Rossby waves. However, in the non linear frame it is not necessarily true.

Poleward energy flux. The poleward energy flux $\left(t_{P}\right)$, across a given latitude $+\theta_{0}$ is given by:

$t_{p_{\text {(linear) }}}=\sum_{\lambda=-\lambda_{0}}^{\lambda=\lambda_{\text {coast }}} \frac{g^{\prime} h H_{0} v}{g^{\prime}} \cos \theta_{0} \Delta \lambda$

$t_{p \text { (non-linear) }}=\sum_{\lambda=-\lambda_{0}}^{\lambda=\lambda_{\text {coast }}} \overline{\left(g^{\prime} h+q\right) V} r \cos \theta_{0} \Delta \lambda$

where the overbar denotes time average; $h(\lambda, \theta, t)$ is the interface displacement of the upper layer to the mean depth $H_{0}(\lambda, \theta) ; u(\lambda, \theta, t)$ and $v(\lambda, \theta, t)$ are the horizontal components of the depth averaged velocity vector $v(\lambda, \theta$, $t)$ in the $\lambda$ (east-east) and $\theta$ (north-south) directions, respectively. Reduced gravity is $g^{\prime}=g\left(\rho_{2}-\rho_{1}\right) / \rho_{2}$, where $g=9.8 \mathrm{~m} / \mathrm{s}$ is the acceleration of gravity; $\rho_{2} e \rho_{1}$ are the density of the upper and lower layers, respectively. The radius of the Earth is taken to be a constant, $r=6.37 \times 10^{6} \mathrm{~m} ; \boldsymbol{V}(\lambda, \theta, \mathrm{t})=u H \mathbf{i}+v H \mathbf{j}=U \mathbf{i}+V \mathbf{j}$ and $q=\left(u^{2}+v^{2}\right) / 2$ (kinetic energy per unit of area).

Net energy flux in the east-west direction. The net energy flux $(t)$, toward the boundary across a given longitude $-\lambda_{0}$, can be given by:

$$
\begin{gathered}
t_{\text {(linear) }}=t_{E(\text { linear })}-t_{W(\text { linear })}=\sum_{\theta=-\theta_{0}}^{\theta=+\theta_{0}} \overline{g^{\prime} h H_{0} u} r \Delta \theta \\
t_{(\text {non-linear })}=t_{E(\text { non-linear })}-t_{W(\text { non-linear })} \\
=\sum_{\theta=-\theta_{0}}^{\theta=+\theta_{0}} \overline{\left(g^{\prime} h+q\right) U} r \Delta \theta
\end{gathered}
$$

The direct determination of $t=t_{E}-t_{W}$, however, is computationally expensive because the propagation speed of the westward Rossby waves is a strong function of the latitude varying from $\sim 0.8 \mathrm{~m} / \mathrm{s}$ at the equator to zero at the poles. It could take years of numerical integration for all the Rossby waves, generated at the eastern boundary, to reach the western side of the domain. To save computer time, first $t_{E}$ is calculated and then $t_{W}$ is inferred by energy conservation considerations. The energy input in the experiment is only due to the baroclinic equatorial Kelvin wave. Consequently before the reflection of this wave at the eastern coast, the eastward energy flux through a given longitude of the numerical domain corresponds to the value of $t_{E}$. It can be assumed that the reflected Rossby wave energy $\left(t_{W}\right)$, for one hemisphere, is given by $t_{W} / 2=t_{E} / 2-t_{P}-t_{D} / 2$.

Energy dissipation. The dissipation of energy $\left(t_{D}\right)$, up to a given latitude $+\theta_{0}$, can be calculated as: 


$$
\begin{aligned}
& t_{D \text { (linear) }} \\
& \quad=-\sum_{\lambda=-\lambda_{0}}^{\lambda=\lambda_{\text {coast }}} \sum_{\theta=-0}^{\theta=+\theta} \overline{A_{H} H_{0}\left(u \nabla^{2} u+v \nabla^{2} v\right)} r^{2} \cos \theta \Delta \theta \Delta \lambda
\end{aligned}
$$

$$
\begin{aligned}
& t_{D(\text { non-linear })} \\
& \quad=-\sum_{\lambda=-\lambda_{0}}^{\lambda=\lambda_{\text {coast }}} \sum_{\theta=0}^{\theta=+\theta} \overline{A_{H} H\left(u \nabla^{2} u+v \nabla^{2} v\right)} r^{2} \cos \theta \Delta \theta \Delta \lambda
\end{aligned}
$$

where $H(\lambda, \theta, t)$ is the total depth $\left(H=H_{0}+h\right)$ and $\nabla^{2}$ is the Laplacian operator in spherical coordinates.

Equations (1), (2), (5) and (6) consider only the Northern Hemisphere. Changing $\theta=+\theta_{0}$ for $\theta=-\theta_{0}$ in those expressions gives the Southern Hemisphere fluxes. The energy input is always considered for both Hemispheres and the poleward, westward and energy dissipations are always calculated for the Hemisphere in consideration.

\subsection{Model Pacific Ocean results}

3.2.1 Intraseasonal variability. In the linear and non linear experiments described in this section the latitudinal model basin extents from $-20^{\circ}$ to $20^{\circ}$ and has a maximum longitudinal extent of $70^{\circ}$. The eastern Pacific boundary approximation used in the intraseasonal experiments can be seen in Fig. 1a.

A baroclinic equatorial Kelvin wave of 60-day period is used as an initial condition of the numerical model for the intraseasonal linear and non linear cases. The numerical model is integrated for 90 days.
The linear northward energy flux $\left(t_{N}\right)$ and the Northern Hemisphere dissipation of energy $\left(t_{D}\right)$ were numerically calculated using Eqs. (1) and (5) respectively; $t_{S}$ (southward energy flux) and $t_{D}$ (dissipation) for the Southern Hemisphere were obtained using the same equations but with $\theta=-\theta_{0}$.

The nondimensional energy flux coefficients (in \%) $r_{\mathrm{P}}(\gamma, T), r_{W}(\gamma, T)$ and $r_{D}(\gamma, T)$ shown in Fig. 2, are, respectively, the ratios of the poleward (northward or southward depending on the hemisphere) coastal Kelvin wave, of reflected Rossby wave and of the dissipation of energy fluxes to the incoming equatorial Kelvin wave energy flux (i.e., $r_{P}=t_{P} / t_{E}, r_{W}=t_{W} / t_{E}$ and $r_{D}=t_{D} /$ $\left.t_{E}\right)$. The coefficients are calculated at latitudinal intervals of $2^{\circ}$ and integrated in time for 90 days.

To investigate the effect of the nonlinear terms on low frequency wave reflection at the Pacific boundary, the non linear model is run using the same parameters and the same initial condition as used for the linear case. The non linear poleward coastal Kelvin wave energy flux $\left(t_{P}\right)$ and the dissipation of energy $\left(t_{D}\right)$ are estimated, for both-hemispheres, using Eqs. (2) and (6).

Figure $2 \mathrm{a}$ shows the westward energy fluxes calculated using (1) the Pacific coastline and the linear model (PAC-L); (2) meridional coastline and the linear model (C0-L); (3) Pacific coastline and the non linear model (PAC-NL) and (4) meridional coastline and the non linear model ( $\mathrm{C} 0-\mathrm{NL})$.

Figure 2 shows the westward flux (Fig. 2a), poleward flux (Fig. 2b) and dissipation coefficient (Fig. 2c). It can be seen that the changes in energy fluxes and in energy dissipation induced by the coastline geometry are notably more important than those induced by the nonlinearities.

For the cases investigated, and within the confines of this model, the linear and nonlinear poleward energy
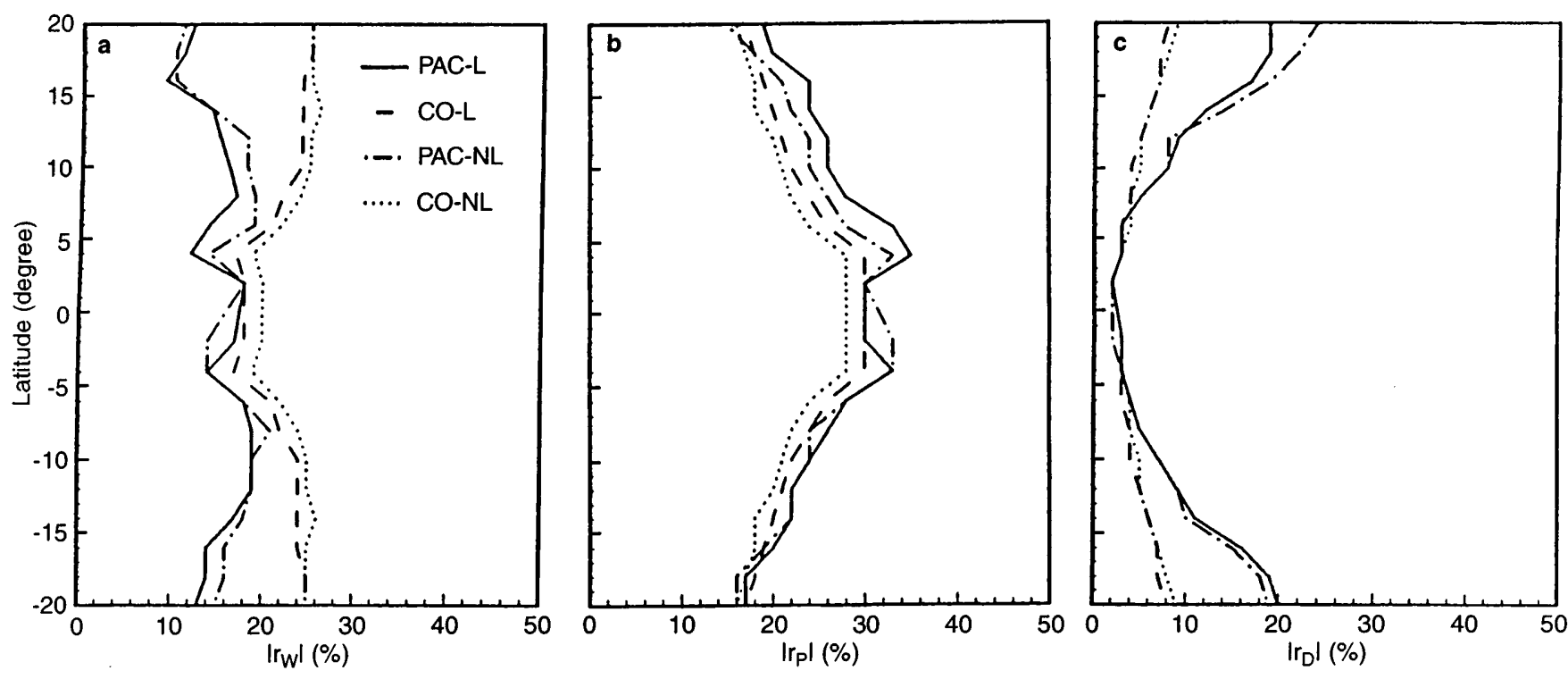

Fig. 2a-c. Energy flux coefficients (\%) at different latitudes (degree). $\mathbf{a} r_{W}, \mathbf{b} r_{P}$ and $\mathbf{c} r_{D}$. Solid line: linear experiment with Pacific coastline $(P A C-L)$. Dashed line: linear experiment with meridional coastline
(CO-L). Center-dashed line: non linear experiment with Pacific coastline $(P A C-N L)$. Dotted line: non linear experiment with meridional coastline $(C 0-N L)$. Wave period: 60 days 
fluxes do not present considerable differences; the smallest values are given when the coastline is meridional in the nonlinear model and the largest for the Pacific coastline in the linear model.

For an inclined boundary, it would be expected from inviscid theory, that the poleward propagation of coastal waves would be enhanced compared with the meridional boundary. However, as discussed in Soares et al. (1998), the dissipation induced by the inclined boundary is larger than that induced by the meridional one (see Fig. 2c). Hence, for the Pacific coastline the expected rise in poleward energy flux induced by the inclined boundary, is offset by dissipation.

The Pacific northward energy flux is a somewhat larger than the southward energy flux whereas the westward energy flux is smaller in the Northern Hemisphere than in the Southern Hemisphere (Fig. 2). This is consistent with the northern Pacific boundary being more nonmeridional (see Soares et al., 1998). The Pacific energy dissipation is roughly similar in both hemispheres. Its westward energy flux presents a considerable latitudinal variation because of the changing coastline angle. This allows more than one critical latitude (in agreement with Grimshaw and Allen, 1988; Clarke and Shi, 1991; Clarke, 1992).

Furthermore, in Fig. 2a we note that the Pacific coastline is less reflective than the meridional boundary. This is expected because inclined boundaries favor trapped motion more than meridional ones.

Since the energy fluxes discussed are affected more by the coastline geometry than by the nonlinearities, hereafter only the linear cases are investigated.

3.2.2 Seasonal variability. To simulate the seasonal variability in the eastern Pacific ocean an equatorial Kelvin wave of 180 days period is used as an initial condition of the numerical model. The modelled region in this experiment is from $45^{\circ} \mathrm{S}$ to $45^{\circ} \mathrm{N}$ and has a maximum longitudinal extent of $140^{\circ}$ (see Fig. 1b for the boundary geometry).

The nondimensional energy flux and the energy dissipation coefficients generated at the Pacific coastline (PAC) are shown in Fig. 3 together with the energy fluxes generated at a meridional boundary $(\mathrm{C} 0)$. The coefficients were calculated at every $5^{\circ}$ of latitude and integrated over 6 months. The asymmetry between the Pacific Northern and Southern Hemispheres is small. Poleward of $\sim 20^{\circ}$ of latitude, the dissipation of energy is larger than the energy fluxes.

In agreement with the intraseasonal period experiment, the Pacific boundary is less reflective than the meridional boundary (Fig. 3a). The Pacific poleward energy flux (Fig. 3b) is slightly smaller than that generated at the meridional boundary because of the larger dissipation of energy occurring in the Pacific (Fig. 3c) and, thus, preventing the increase of poleward energy flux induced by the coastline geometry.

3.2.3 Annual variability. An equatorial Kelvin wave of 360 days period is used as an initial condition of the linear numerical model experiment. Following the previous case, the poleward energy flux and the dissipation of energy were numerically calculated for every $5^{\circ}$ of latitude and integrated over 8 months. Since only half a wavelength is used as initial condition, it takes around 7 months of the integration period for all the poleward energy to leave the numerical domain.

The nondimensional energy fluxes and the nondimensional energy dissipation (PAC) are displayed in Fig. 4 together with the fluxes generated at the meridional boundary $(\mathrm{C} 0)$.

In the northern Pacific, the westward energy flux differs substantially from that generated at the meridional boundary (Fig. 4a). Inviscid theory suggests that
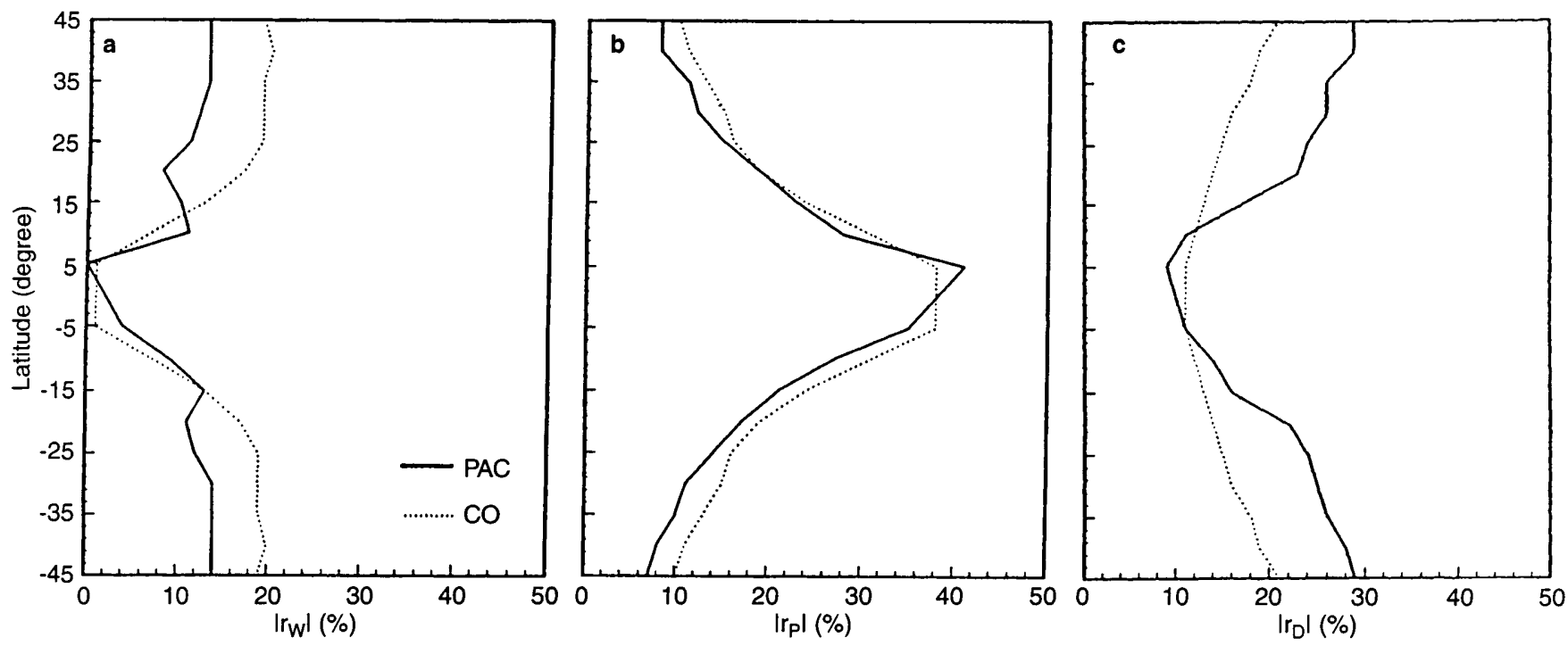

Fig. 3a-c. Linear energy flux coefficients (\%) at different latitudes (degree). a $r_{W}, \mathbf{b} r_{P}$ and $\mathbf{c} r_{D}$. Solid line: Pacific coastline (PAC). Dotted line: meridional boundary $(C 0)$. Wave period: 180 days 

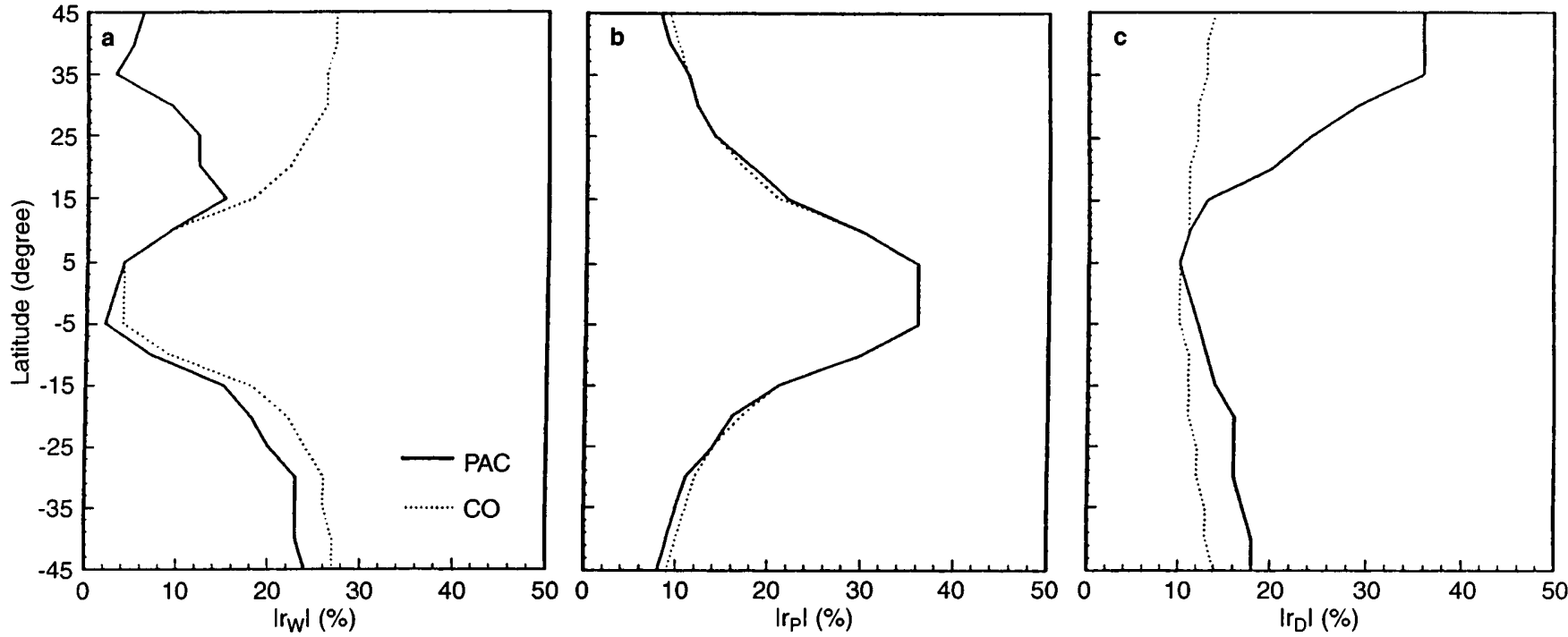

Fig. 4a-c. Linear energy flux coefficient (\%) at different latitudes (degree). a $r_{W}, \mathbf{b} r_{P}$ and $\mathbf{c} r_{D}$. Solid line: Pacific coastline (PAC). Dotted line: meridional boundary $(C O)$. Wave period: 360 days

trapped motion is expected to be favored given that the northern Pacific coastline is less reflective than the meridional boundary, or than the southern Pacific coastline. However, from Fig. $4 \mathrm{~b}$, this is not the case. What happens is that the dissipation of energy (which increases as the boundary departs from the meridional direction; see Fig. 4c), restrains the increase in the northward energy flux induced by the coastline geometry.

The annual northward and southward energy fluxes, at the Pacific Ocean, are symmetric in relation to the equator (Fig. $4 \mathrm{~b}$ ). Above $20^{\circ} \mathrm{N}$, the dissipation of energy is dominant over the energy fluxes. In the Southern Hemisphere, however, the coastline geometry facilitates the boundary reflection and, poleward of $20^{\circ} \mathrm{S}$, the westward energy flux is larger than the dissipation of energy. In the south Pacific, the energy fluxes and the energy dissipation are not substantially different from those generated in the meridional boundary experiment. This is because the southern Pacific coastline does not depart significantly from the north-south direction.

3.2.4 Discussion. Figure 5 summarizes the energy fluxes and the energy dissipation coefficients obtained for the Pacific Ocean at intraseasonal (T60), seasonal (T180) and annual (T360) periods. The intraseasonal coefficients were calculated only up to $20^{\circ}$ of latitude and therefore a direct comparison between the intraseasonal coefficients and the lower frequency coefficients should be made with prudence.

The energy fluxes are strongly dependent on the energy dissipated in the domain, as shown by Soares
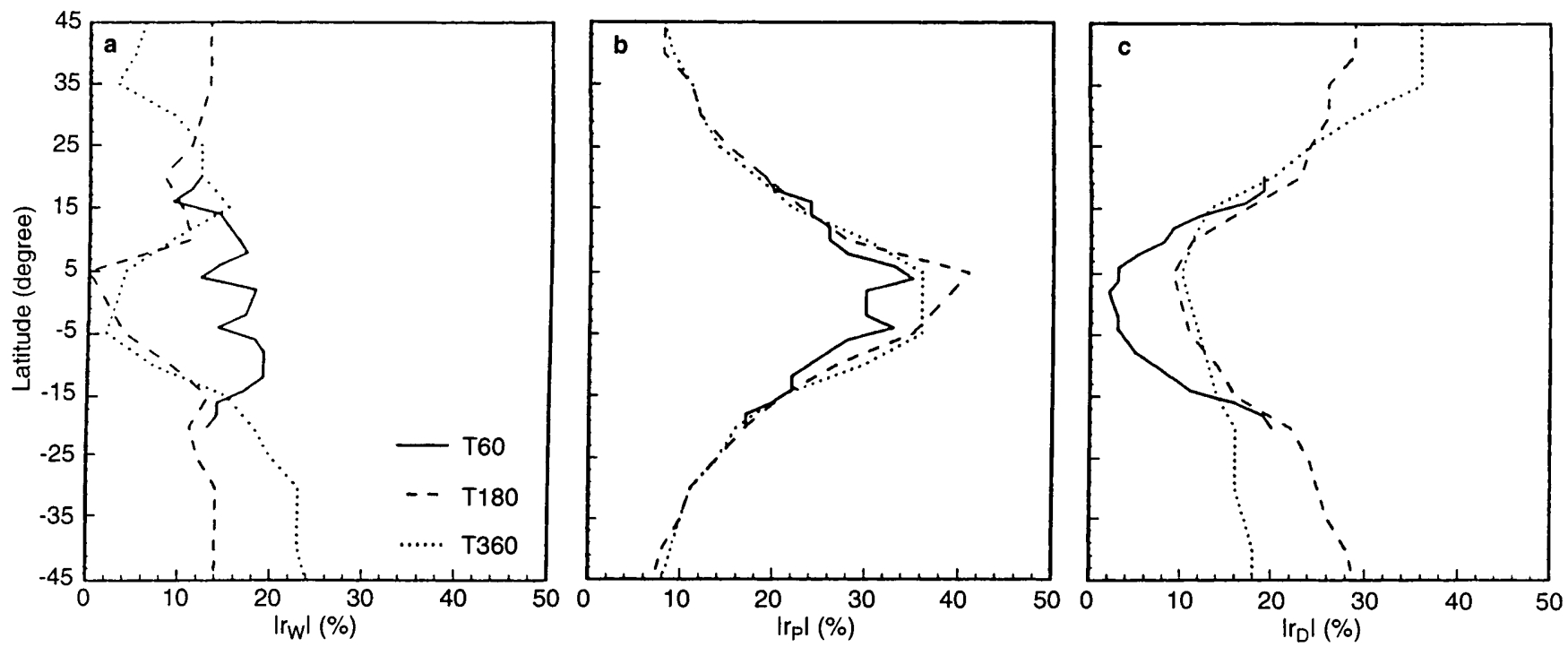

Fig. 5a-c. Linear energy flux coefficients (\%) at different latitudes (degree) for different incident wave periods. a $r_{W}$, b $r_{P}$ and $\mathbf{c} r_{D}$. Pacific boundary 
et al. (1998). In the Southern Hemisphere, the dissipation of energy is smaller in the annual experiment than in the seasonal one (Fig. 5c). This is explained by the critical latitude values being higher for the annual experiment. Therefore, the increase in dissipation due to the increase of wave period is shown to be less important than the energy dissipated by the presence of coastal Kelvin waves. In the Northern Hemisphere, however, the energy dissipated in the annual case is larger than that for the seasonal case. This is, probably, due to the combination of both factors, the presence of the coastal Kelvin waves in the domain and the increase in the wave period.

The intraseasonal (T60) values of $r_{W}$ (Fig. 5a) and $r_{D}$ (Fig. 5c) are, respectively, larger and smaller than those obtained by the lower frequency experiments.

The westward energy flux, in the Southern Hemisphere, is larger for the annual period experiment (T360) than for the seasonal period (T180) case. In the Northern Hemisphere (where the boundary is more nonmeridional) the comparatively larger presence of coastal Kelvin waves, in the annual period experiment, induces stronger dissipative effects (see Fig. 5c) inhibiting the reflection processes. As a result, less energy of annual period is leaked offshore (Fig. 5a). According to inviscid studies (Clarke and Shi, 1983; Clarke, 1992) the poleward energy flux decreases and the westward energy flux increases as the incident Kelvin wave period is increased. However, calculations for the intraseasonal, seasonal and annual frequencies all indicate that the coastally trapped energy flux, poleward of $15^{\circ}$, does not depend significantly on the period of the incident wave (Fig. 5b).

In contrast to inviscid theory, there is symmetry between the northward and southward energy fluxes for all frequencies. The symmetry of $r_{P}$ can be accounted for the larger dissipative effects in the Northern Hemisphere which compensates for the increase of the northward energy flux generated by the coastline geometry, and hence results in similar $r_{P}$ values for both hemispheres.

The hemispherical asymmetry of both, westward energy flux and energy dissipation, is greater for the annual experiment. This result is in agreement with Clarke (1992) who found that the energy flux asymmetry in the eastern Pacific increases as the wave period increases.

\subsection{Model Atlantic Ocean results}

The experiments carried out for the eastern Pacific Ocean coastline are now repeated for the eastern Atlantic Ocean coastline. The methodology employed is similar to that utilized in the previous experiment.

The Atlantic coastline geometry can be seen in Fig. 1c (intraseasonal period) and 1d (seasonal and annual periods).

3.3.1 Intraseasonal variability. The intraseasonal nondimensional linear and non linear energy flux coefficients, $r_{P}(\gamma, T), r_{W}(\gamma, T)$ and $r_{D}(\gamma, T)$ generated at both, Atlantic boundary and meridional boundary, are shown in Fig. 6 at different latitudes. The coefficients are calculated at latitudinal intervals of $2^{\circ}$ and integrated over 90 days. The energy coefficients are calculated using the: (1) Atlantic coastline and the linear model (ATL-L); (2) meridional coastline and the linear model (CO-L); (3) Atlantic coastline and the non linear model (ATL-NL) and (4) meridional boundary and the non linear model (C0-NL).

In agreement with the earlier experiments, the energy flux changes induced by the coastline geometry are significantly more important than those induced by nonlinearities (Fig. 6).
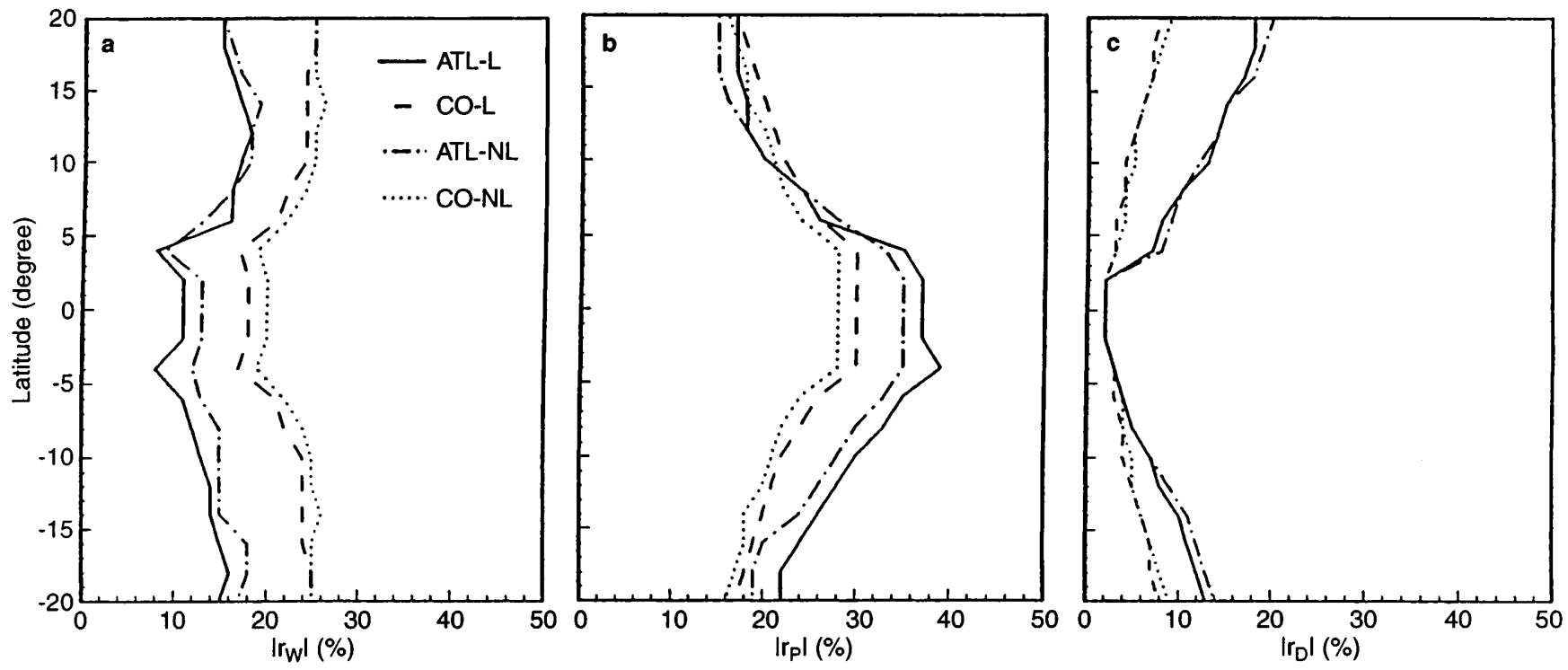

Fig. 6a-c. Energy flux coefficient (\%) at different latitudes (degree). a $r_{W}, \mathbf{b} r_{P}$ and $\mathbf{c} r_{D}$. Solid line: linear experiment with Atlantic coastline $(A T L-L)$. Dashed line: linear experiment with meridional coastline
(CO-L). Center-dashed line: non linear experiment with Atlantic coastline $(A T L-N L)$. Dotted line: non linear experiment with meridional coastline $(C 0-N L)$. Wave period: 60 days 
Near the Gulf of Guinea, the reflected energy flux and the dissipated energy, both exhibit a rapid increase whereas the poleward energy flux shows a rapid decrease. The rise in the $r_{D}$ value is due to the energy dissipated along the zonal boundary (see Fig. 6b). The larger amount of dissipation reduces the northward energy flux.

The Atlantic coastline is shown by Fig. 6a to be less reflective than the meridional one. This result is theoretically expected (Soares et al., 1998) given that the critical latitudes for the nonmeridional boundaries are lower than those generated at the meridional coastlines.

For all the cases examined in Fig. 6b, north of $5^{\circ} \mathrm{N}$, the northward energy fluxes are similar, and hence, poleward of $5^{\circ} \mathrm{N}$, the Northern Atlantic coastline acts as a meridional boundary. In the Southern Hemisphere, the poleward energy generated in the Atlantic coastline is larger than that generated at the meridional boundary. In agreement with the earlier experiments the energy dissipation induced by the nonmeridional boundary (Atlantic coastline) is larger than that induced by the meridional one (Fig. 6c). The increase in dissipation reduces the expected rise in the poleward energy flux induced by the geometry of the coastline.

3.3.2 Seasonal variability. To compare the energy flux changes induced by the coastline geometry, the Atlantic energy flux coefficients (ATL) are shown in Fig. 7 with the corresponding fluxes generated at the meridional boundary $(\mathrm{C} 0)$. The coefficients are calculated at every $5^{\circ}$ of latitude and integrated over 6 months. The asymmetry between the Northern and Southern Hemispheres is found to be negligible for all the seasonal energy fluxes investigated here. It indicates that the geometrical effects of the Gulf of the Guinea are not very important for seasonal period motions.
As for the intraseasonal period experiment, the Atlantic boundary is less reflective than the meridional boundary (see Fig. 7a). According to Fig. 7b, with respect to the seasonal poleward energy flux the whole eastern Atlantic boundary can be roughly regarded as a meridional boundary. Again, the comparatively larger energy dissipated at the Atlantic boundary (Fig. 7c) obstructs the expected increase of poleward energy flux induced by the coastline geometry.

3.3.3 Annual variability. To compare the coastline influences on the energy fluxes and on the energy dissipation, the nondimensional coefficients generated by the Atlantic coastline (ATL) and by a meridional boundary $(\mathrm{C} 0)$ are displayed together in Fig. 8. In common with the seasonal experiment, all the annual energy coefficients, generated at the Atlantic eastern coast, are approximately symmetric with respect to the equator.

The annual poleward energy fluxes induced by both, meridional and Atlantic boundaries, are very similar. As expected, the energy dissipated (Fig. 8c) and the reflected flux (Fig. 8a) are, respectively, larger and smaller at the Atlantic boundary compared with the meridional boundary.

3.3.4 Discussion. The intraseasonal, seasonal and annual energy fluxes and energy dissipation coefficients are summarized in Fig. 9. In agreement with Fig. 5 the westward energy flux is larger for the intraseasonal period than for longer periods (Fig. 9a). This is because of the lower values of energy dissipated, in the domain, at the intraseasonal period (Fig. 9c).

As the wave period increases, from seasonal to annual, the reflected energy increases (Fig. 9a) and the dissipation of energy decreases (Fig. 9c) because of the
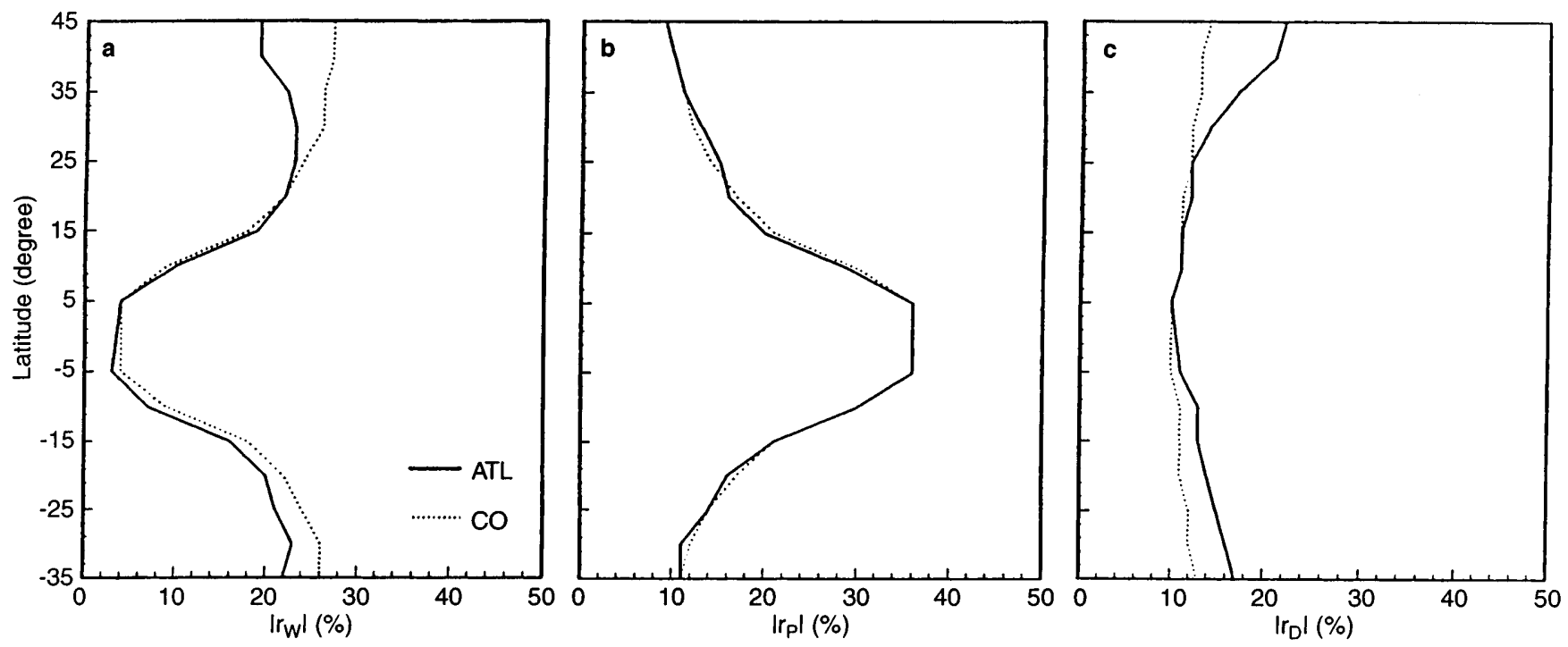

Fig. 7a-c. Linear energy flux coefficient (\%) at different latitudes (degree). a $r_{W}, \mathbf{b} r_{P}$ and $\mathbf{c} r_{D}$. Solid line: Atlantic coastline (ATL). Dotted line: meridional boundary $(C)$. Wave period: 180 days 

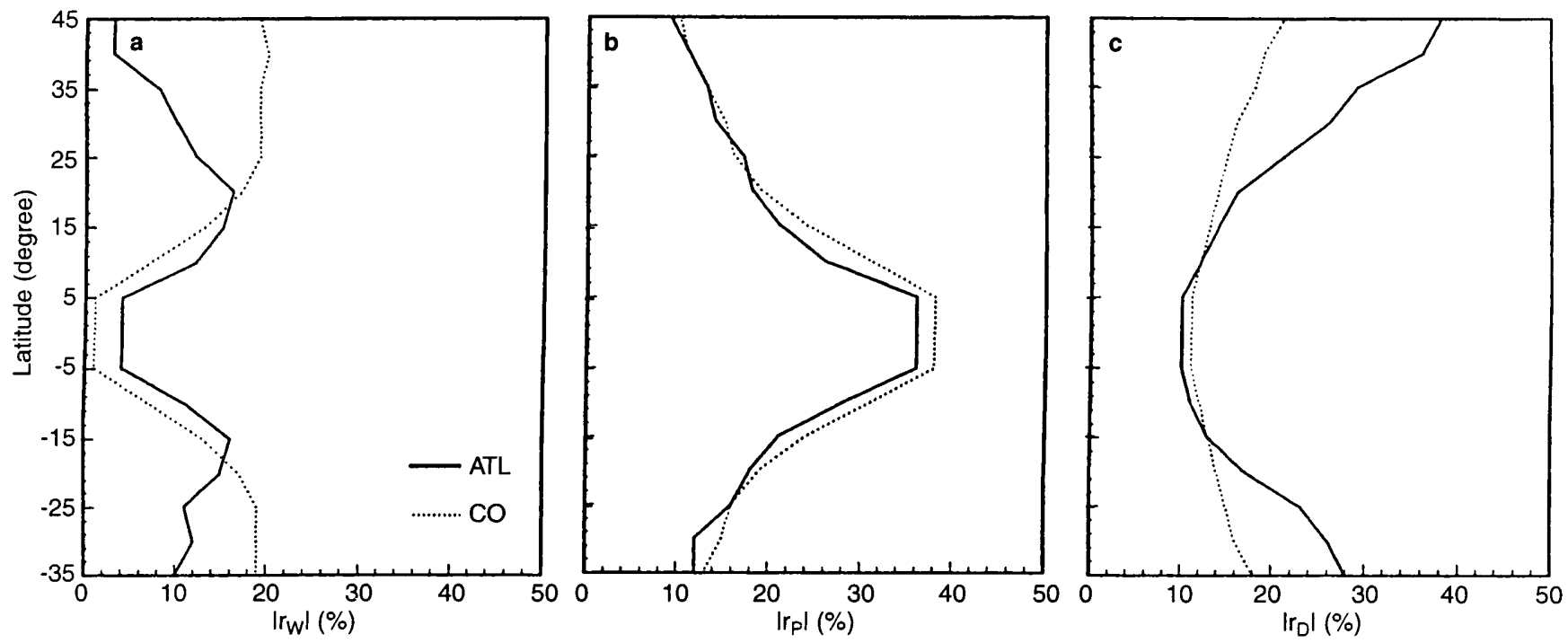

Fig. 8a-c. Linear energy flux coefficient (\%) at different latitudes (degree). a $r_{W}, \mathbf{b} r_{P}$ and $\mathbf{c} r_{D}$. Solid line: Atlantic coastline (ATL). Dotted line: meridional boundary $(C O)$. Wave period: 360 days
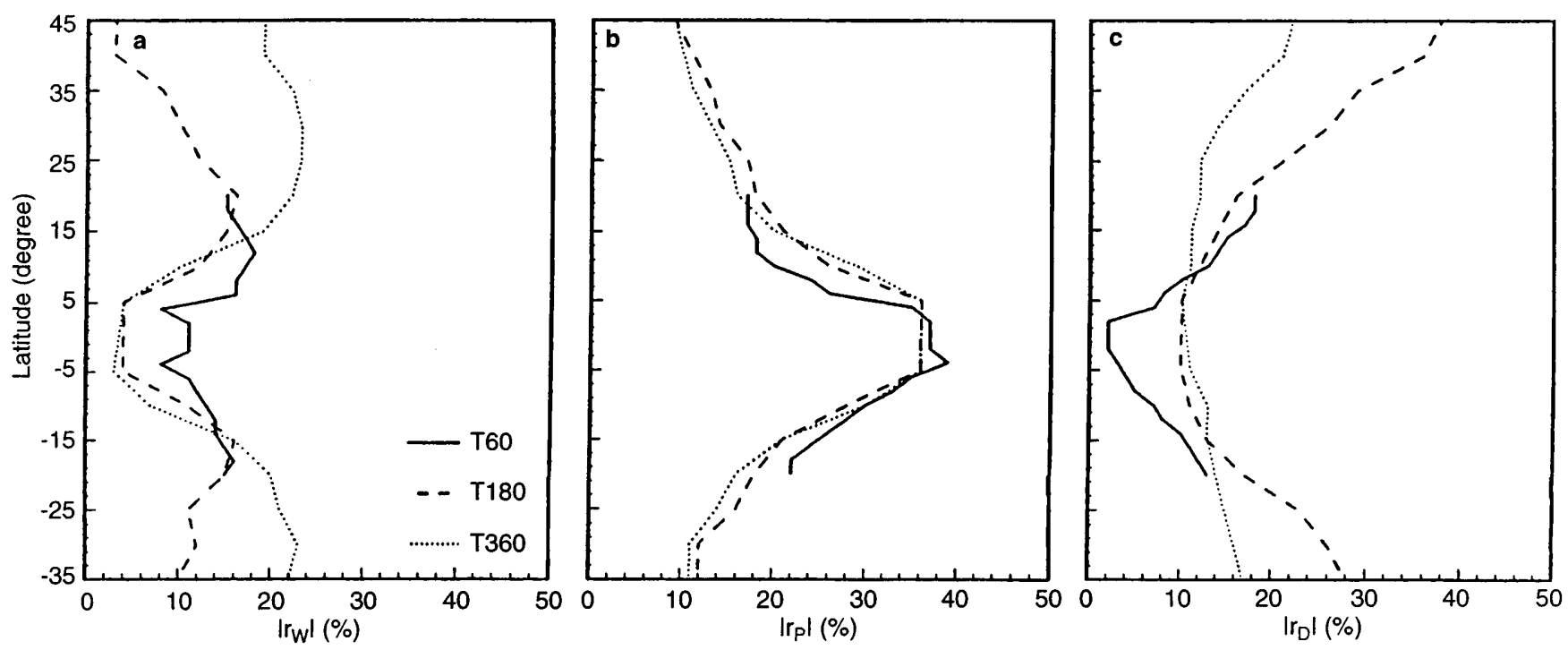

Fig. 9a-c. Linear energy flux coefficient (\%) at different latitudes (degree) for different incident wave periods. a $r_{W}$, b $r_{P}$ and $\mathbf{c} r_{D}$. Atlantic boundary

increase of the critical latitude with the lengthening of the wave period. As the critical latitude increases, there is more energy in the westward Rossby waves and, consequently, smaller amount of energy dissipated in the domain.

It is found that the seasonal and the annual poleward energy fluxes are very similar (Fig. 9b). Both fluxes are also comparable to the poleward energy flux generated at the meridional boundary (see Figs. 7b, 8b). Despite the reflected energy being smaller for the seasonal case than for the annual experiment, the seasonal energy dissipated in the domain is larger, resulting in similar values of the poleward energy fluxes for both periods.

The influence of the Atlantic coastline geometry, therefore, on the seasonal and annual coastally trapped energy flux can be considered to be small. This result is striking because of the particular geometry of the eastern Atlantic, which has an approximately zonal coast near $5^{\circ} \mathrm{N}$ (Gulf of the Guinea). Du Penhoat et al. (1983) have also shown that the effect of the coast of the Gulf of Guinea is small on very low frequency waves (seasonal and annual periods).

The largest asymmetry between the Northern and Southern Hemisphere energy fluxes has been found in the intraseasonal experiment. At intraseasonal periods the effects of the Atlantic coastline geometry are to cause an enhancement of the poleward energy flux and a reduction in Rossby waves generation, between $20^{\circ} \mathrm{S}$ and $5^{\circ} \mathrm{N}$. The flow produced by the coastal Kelvin wave along of the approximately zonal boundary of the Gulf of Guinea also contributes to this result. 


\section{Conclusions}

The effect of the coastline geometry and the incident wave period (intraseasonal, seasonal and annual periods), was found to be more important for the westward energy flux than for the poleward flux. To simulate accurately the reflected Rossby waves on the Pacific and Atlantic boundaries, the eastern ocean coastline geometry should be included in the numerical models.

The effect of the inclination of the eastern boundary on the poleward energy flux, for the Pacific and Atlantic oceans, diminishes as the period of the incident wave increases. For motions of seasonal and annual periods, the influence of the coastline inclination, on both oceans, can be considered negligible.

For incident waves of intraseasonal period, however, there is a poleward energy flux asymmetry between the Northern and Southern Hemispheres. For the Northern Atlantic, poleward of $5^{\circ} \mathrm{N}$, the eastern boundary can be considered as a meridional one whereas for the Southern Atlantic the eastern coastline geometry should be incorporated to obtain accurate poleward propagation of intraseasonal period. In the Pacific Ocean, the northward energy flux was found to be somewhat larger than the northward flux generated at a meridional boundary. In the Southern Hemisphere, the difference between the poleward fluxes, of intraseasonal period, generated at the meridional and the Pacific coastlines, however, are considered negligible.

Acknowledgements. J. Soares wishes to thank the Conselho Nacional de Desenvolvimento Cientifico e Tecnologico, CNPQ (Brasilia, Brazil) for the financial support through scholarship 260102/89.0. Part of this work was supported by grant FAPESP 93/1387-0 and CNPQ 300223/93-5 RN.

Topical Editor D. J. Webb thanks G. Bigg and another reference for their help in evaluating this paper.

\section{References}

Adamec, D., and J. J. O'Brien, The seasonal upwelling in the Gulf of Guinea due to remote forcing, J. Phys. Oceanogr., 8, 10501060, 1978.

Bigg, G. R., and A. E. Gill, The annual cycle of sea level in the eastern tropical Pacific, J. Phys. Oceanogr., 16, 1055-1061, 1986.

Busalacchi, A. J., and J. Picaut, Seasonal variability from a model of the tropical Atlantic ocean, J. Phys. Oceanogr., 13, 15641588, 1983.

Chelton, D. B., and R. E. Davis, Monthly mean sea level variability along the west coast of North America, J. Phys. Oceanogr., 12, 757-784, 1982.

Clarke, A. J., Low-frequency reflection from a nonmeridional eastern ocean boundary and the use of coastal sea level to monitor eastern Pacific equatorial Kelvin waves, J. Phys. Oceanogr., 22, 163-183, 1992.

Clarke, A. J., and C. Shi, Critical frequencies at ocean boundaries, J. Geophys. Res., 96, 10 731-10 738, 1991.

Davey, M. K., W. W. Hsieh, and R. C. Wajsowicz, The free Kelvin wave with lateral and vertical viscosity, J. Phys. Oceanogr., 13, 2182-2190, 1983

Delcroix, T., J. Picaut, and G. Eldin, Equatorial Kelvin and Rossby waves evidenced in the Pacific ocean through Geosat sea level and surface current anomalies, J. Geophys. Res., 96, 3249-3262, 1991.

Du Penhoat, Y., M. A. Cane, and R. J. Patton, Reflections of low frequency equatorial waves on partial boundaries, 237-258, in Hydrodynamics of the equatorial ocean, Elsevier Oceanography Series, Elsveier, Amsterdam, 1983.

Enfield, D. B., El Niño, past and present, Rev. Geophys., 27, 159187, 1989.

Enfield, D. B., and J. S. Allen, On the structure and dynamics of monthly mean sea level anomalies along the Pacific coast of North and South America, J. Phys. Oceanogr., 10, 557-588, 1980.

Glantz, M. H., R. W. Katz, and N. Nicholls, Teleconnections linking worldwise climate anomalies, Cambridge University Press, Cambridge, UK, 1990.

Grimshaw, R., and J. S. Allen, Low-frequency baroclinic waves off coastal boundaries, J. Phys. Oceanogr., 18, 1124-1143, 1988.

Hsieh, W. W., M. K. Davey, and R. C. Wajsowicz, The free Kelvin wave in finite-difference numerical models, J. Phys. Oceanogr., 13, 1383-1397, 1983

Houghton, R. W., Circulations and hydrographic structure of the Ghana continental shelf during the 1974 upwelling, J. Phys. Oceanogr., 6, 909-924, 1976.

Johnson, M. I., and J. J. O'Brien, The northeast Pacific Ocean response to the 1982-1983 El Niño, J. Geophys. Res., 95, 71557166, 1990.

Katz, E. J., Equatorial Kelvin waves in the Atlantic, J. Geophys. Res., 92, 1894-1898, 1987.

Madden, R. A., and P. R. Julian, Detection of a 40-50 day oscillation in the zonal wind in the tropical Pacific, J. Atmos. Sci., 28, 702-708, 1971.

Madden, R. A., and P. R. Julian, Description of global scale circulation cells in the tropics with a 40-50 day period, $J$. Atmos. Sci., 29, 1109-1123, 1972.

McCreary, J. P., Eastern tropical ocean response to changing wind systems, J. Phys. Oceanogr., 6, 632-645, 1976.

McCreary, J. P, J. Picaut, and D. W. Moore, Effects of remote annual forcing in the eastern tropical Atlantic ocean, J. Mar. Res., 42, 45-81, 1984.

McPhaden, M. J., and B. Taft, Dynamics of seasonal and intraseasonal variability in the eastern equatorial Pacific, $J$. Phys. Oceanogr., 18, 1713-1732, 1988.

Miller, M. J., and A. J. Thorpe, Radiation conditions for the lateral boundaries of limited-area numerical models, Q.J. R. Meteorol. Soc., 107, 615-628, 1981.

Miller, L., R. Cheney, and B. Douglas, GEOSAT altimeter observations of Kelvin waves and the 1986-87 El Niño, Science, 239, 52-54, 1988.

Moore, D., Planetary-gravity waves in an equatorial ocean. PhD Thesis, Harvard University, Cambridge, Massachusetts, USA, 1968.

Moore, D., and S. G. H. Philander, Modelling of the tropical ocean circulation, in The Sea, vol 6, pp. 319-361, Wiley, New York, 1977.

Moore, D., P. Hisard, J. McCreary, J. Merle, J. O'Brien, J. Picaut, J.-M. Verstraete, and C. Wunsch, Equatorial adjustment in the eastern Atlantic, Geophys. Res. Lett., 5, 637-640, 1978.

Orlanski, I., A simple boundary condition for unbounded hyperbolic flows, J. Comp. Phys., 21, 251-269, 1976.

Pares-Sierra, A., and J. J. O'Brien, The seasonal and interannual variability of the California current system: a numerical model, J. Geophys. Res., 94, 3159-3180, 1989.

Picaut, J., Propagation of the upwelling in the eastern equatorial Atlantic, J. Phys. Oceanogr., 13, 18-37, 1983.

Ripa, P., and S. Hayes, Evidence for equatorially trapped waves at the Galapagos Islands, J. Geophys. Res., 86, 6509-6516, 1981.

Servain, J., J. Picaut, and J. Merle, Evidence of remote forcing in the equatorial Atlantic ocean, J. Phys. Oceanogr., 12, 457-463, 1982.

Soares, J., On the reflection of the equatorial waves at eastern ocean boundaries. PhD Thesis, Oceanography Department, University of Southampton, 1994. 
Soares, J., I. Wainer, and N. C. Wells, Reflection of equatorial Kelvin waves at eastern ocean boundaries. Part I: Hypothetical boundaries, Anna. Geophysicae, (in press) 1998.

Spillane, M. C., D. B. Enfield, and J. S. Allen, Intraseasonal oscillations in sea level along the west coast of the Americas, $J$. Phys. Oceanogr., 17, 313-325, 1986.
Verstraete, J. M, The seasonal upwellings in the Gulf of Guinea, Progr. Oceanogr, 29, 1-60, 1992.

Weickman, K. M., El Nino/Southern Oscillation and MaddenJulian (30-60 days) oscillations during 1981-1982, J. Geophys. Res., 96, 3187-3195, 1991. 